\title{
Evaluation of wind resource potential using statistical analysis of probability density functions in New South Wales, Australia
}

\author{
Nour Khlaifat $^{1}$, Ali Altaee ${ }^{2 *}$, John Zhou ${ }^{3}$, Yuhan Huang ${ }^{4}$ \\ ${ }^{1} \mathrm{PhD}$ Student, ${ }^{2} \mathrm{~A} /$ Professor, ${ }^{3}$ Professor, ${ }^{4}$ Postdoctoral Research Fellow \\ * Correspondence: Email: ali.altaee@uts.edu.au; Tel: +61295142025. \\ Centre for Green Technology, University of Technology Sydney, Sydney, NSW 2007, \\ Australia
}

\begin{abstract}
Wind energy is a vital part of Australia's energy mix. The first step in a wind power project at a particular site is to assess the wind resource potential and feasibility for wind energy production. Research on wind potential and statistical analysis has been done throughout the world. Currently, recent potential wind studies are lacking, especially in New South Wales (NSW), Australia. This study highlighted the feasibility of wind potential at four sites in NSW, namely Ballina, Merriwa, Deniliquin, and the Bega region. The type of wind speed distribution function dramatically affects the output of the available wind energy and wind turbine performance at a particular site. Therefore, the accuracy of four probability density functions was evaluated, namely Rayleigh, Weibull, Gamma, and Lognormal distributions. The outcomes showed Weibull provided the most accurate distribution. The annual average scale and shape parameters of Weibull distribution varied between $2.935-5.042 \mathrm{~m} / \mathrm{s}$ and $1.137-2.096$, respectively. The maximum shape and scale factors were at Deniliquin, while the minimum shape and scale factors were at Bega area. Assessment of power density indicated that Deniliquin had a marginal wind speed resource, while Ballina, Bega, and Merriwa had poor wind resources.
\end{abstract}

Keywords: Probability density function, wind direction, wind potential, statistical analysis, Weibull distribution

1. Introduction

The Australian population was projected to increase to 24.6 million in 2016-2017 based on an annual increase of $1.7 \%$. This rise in the population was reflected in demand for total energy consumption, which grew in $2016-2017$ by $1.1 \%$ to 6,146 petajoules. The energy growth was 65 petajoules, which is equal to the amount of energy equal to filling a petrol tank with a 55 litre capacity, 34 million times [1]. In 2016-2017, the largest share (38\%) of Australia's primary energy was oil, including liquefied petroleum gas, crude oil, and refined products. Coal is the second-largest energy resource (32\%), followed by natural gas $(25 \%)$, while the remaining $6 \%$ of energy consumption originates from renewable energy sources [1]. Therefore, incorporating renewable energy into the national grid is a timely concern for satisfying the rapidly growing energy demand and improving sustainability. 
Renewable energy has attracted the attention of researchers and scientists and has been considered as an alternative method for the power generation to replace fossil fuel power plants. However, it is still not growing as fast as it should. Climate change is a real environmental threat that caused by the increasing greenhouse gas emissions from burning fossil fuels and hence should be reduced by shifting to renewable energies such as wind energy, solar power, hydropower, or bio-fuels. The natural greenhouse effect keeps the Earth warm enough for life to exist. However, the burning of fossil fuels is adding extra $\mathrm{CO}_{2}$ to the atmosphere, and this results in human-made climate change which is making the planet hotter, causing the ice to melt, harming the climate and threatening all living creatures.

Australia has a wide and plentifully distributed wind resource, and some of its locations are considered to be the best in the world. Wind energy is considered to be a renewable energy resource for generating electricity and has attracted much awareness in Australia. Wind power generation has grown greatly in the past decade. On average, wind electricity generation rose by $17 \%$ per year during 2007-2017 [1]. The first step in wind resources utilization is identifying candidate sites for assessment, which includes surveying a large land or a selected region for a particular wind power project. Thus, wind resource assessment is an essential step for predicting the annual energy production and defining the feasibility and profitability of a given wind power project at a specific site. For a wind power project to be successful, the assessment of accurate wind resource is crucial. The statistical analysis method for measured wind speeds is used to specify the wind frequency, using probability density function.

The probability density functions significantly influence the analysis outcome of the available wind resources, which are used to calculate the wind turbine energy production at a particular site. The most popular probability density functions are Rayleigh and Weibull distribution, which are utilized by several researchers for analyzing the wind speed characteristics. Shu et al. [2] utilized the Weibull distribution to assess the wind characteristics in Hong Kong. The outcomes displayed that the scale parameter changed from 2.9 to $10.2 \mathrm{~m} / \mathrm{s}$, where the annual shape parameter varied between 1.65-1.99. The maximum scale parameter was found at a hilltop, while the minimum value was observed at an urban site. Irwanto et al. [3] used Weibull distribution to investigate the wind speed characteristics at Kangar and Chuping in Perlis, Malaysia. Their results revealed that the wind power density at the height of $50 \mathrm{~m}$ was $19.69 \mathrm{~W} / \mathrm{m}^{2}$ and $2.13 \mathrm{~W} / \mathrm{m}^{2}$ at Kangar and Chuping, respectively, and subsequently categorized as poor wind regions. Furthermore, the highest scale parameter of 1.47 occurred in 2005, which was considered the windiest year during 2005-2009. 
Janajreh et al. [4] assessed wind potential using Weibull distribution in Masdar city, UAE. The scale and shape parameters at an elevation of $10 \mathrm{~m}$ were $3.36 \mathrm{~m} / \mathrm{s}$ and 1.56 , respectively. In another study, Teimourian et al. [5] estimated the wind resources using Weibull distribution at Lotak and Shandol in Iran. The scale parameters at the Lotak and Shandol sites were 3.40$11.92 \mathrm{~m} / \mathrm{s}$ and $4.49-12.05 \mathrm{~m} / \mathrm{s}$, respectively. The shape parameters at Lotak and Shandol were 1.51-3.38 and 1.51-3.46, respectively. Elsewhere, Mezidi et al. [6] studied the wind potential at two sites - Adrar and In Salah - located in Algeria's southern part, to measure the wind speed between 2006 to 2015. The Weibull function is applied to evaluate the shape and scale parameters, and these were 2.7 and $6.8 \mathrm{~m} / \mathrm{s}$, respectively, for Adrar and 2.54, $7.4 \mathrm{~m} / \mathrm{s}$ for In Salah, respectively. Ozay and Celiktas [7] highlighted the great potential of wind power in the Alaçatı region, Izmir, Turkey. The measured wind data from 2008 to 2014 were studied using Weibull and Rayleigh distributions. Findings showed that Weibull distribution had the best fit of wind data, with a correlation coefficient of 0.989 . The scale and shape parameters were 9.16 $\mathrm{m} / \mathrm{s}$ and 2.05 , respectively.

Weibull distribution parameters have been calculated using different numerical method. For instance, Rocha et al. [8] assessed the effectiveness of different numerical methods for determining Weibull distribution parameters using measured wind data in the cities of Camocim and Paracuru, Brazil. The result was that equivalent energy method was the best numerical method according to the fitting measured data. Solyali et al. [9] studied the potential of wind power in northern Cyprus using Weibull distribution. Three algorithms served to calculate the shape and scale parameters, including the least squares, maximum likelihood and equivalent energy methods. It emerged that the equivalent energy method was the most accurate.

As reviewed above, most wind power assessment studies used Weibull distribution. The suitability of other distribution functions for fitting measured wind speed data was also investigated. For example, Guerri et al. [10] investigated the performance of wind farm at Kaberten, which is located in the south of Algeria, using probability density distributions of Weibull, Normal, and the generalized extreme value function. The relative errors were $2.5 \%, 5.9 \%$, and $20.9 \%$, respectively. The position has a critical role in the power output of wind turbines. The power output could be enhanced when the design of the horizontal axis wind turbine is based on environmental conditions [11]. For Australian studies, Morgan [12] investigated the wind characteristics at Lindfield, Sydney. Weibull distribution was used for recording wind data over a period lasting 36 months. Katsigiannis and Stavrakakis [13] examined the large scale wind turbine for electricity generation application in Gingin, 
Armidale, and Gold Coast Seaway, Queensland. Maunsell et al. [14] investigated wind resource in Western Australia via the Wind Atlas methodology.

Wind resources vary from one place to another, and they have seasonal and daily variations even for the same location, which explains the need to do a case analysis on the feasibility and potential of wind energy in a specific site. As discussed above, some statistical analysis of wind data resources has been undertaken in different parts of the world. Nonetheless, we lack recent studies using different probability density functions in Australia, especially New South Wales (NSW). This study's main objective is to analyze the statistical characteristics of wind speeds recorded from metrological stations in Ballina, Merriwa, Deniliquin, and the Bega region in NSW. This paper comprehensively highlights the feasibility and classification of wind potential using wind power density and wind speeds variation at various heights. Four probability density functions, namely Rayleigh, Weibull, Gamma, and Lognormal distribution, have been evaluated in depth using statistical parameters to assess their fitness. The comparison reveals the most accurate probability distribution function, which presents the frequency of wind speed. Wind direction and frequency are also assessed for selected sites using wind rose plots.

\section{Methodology}

\subsection{Description of the case study locations and the data used}

Research has indicated that Australia has wind resources that are in places comparable to high wind resources in northern Europe $[15,16]$ as shown in the appendix. Wind energy is a vital part of the NSW energy mix, which has world-class wind resources. Different governments' Sustainable Energy Development legislation was adhered to optimize the usage of renewable energy in NSW. The Sustainable Energy Development Authority (SEDA) aimed to increase investment in the wind energy sector. Most wind energy developments in NSW will be in rural and regional areas. Wind energy is especially attractive to those communities because of the potential for employment, developing industry, and generating income for landholders. In this study, four sites have been selected to create useful insights into the wind potential in NSW. Specifically, Ballina, Bega, Deniliquin, and Merriwa are the four locations be considered for investigation. As seen in Figure 1, the four locations are very far apart in NSW, giving an overall insight into the wind resource potential in NSW. The geographical coordinates of the four meteorological stations are illustrated in Table 1. 


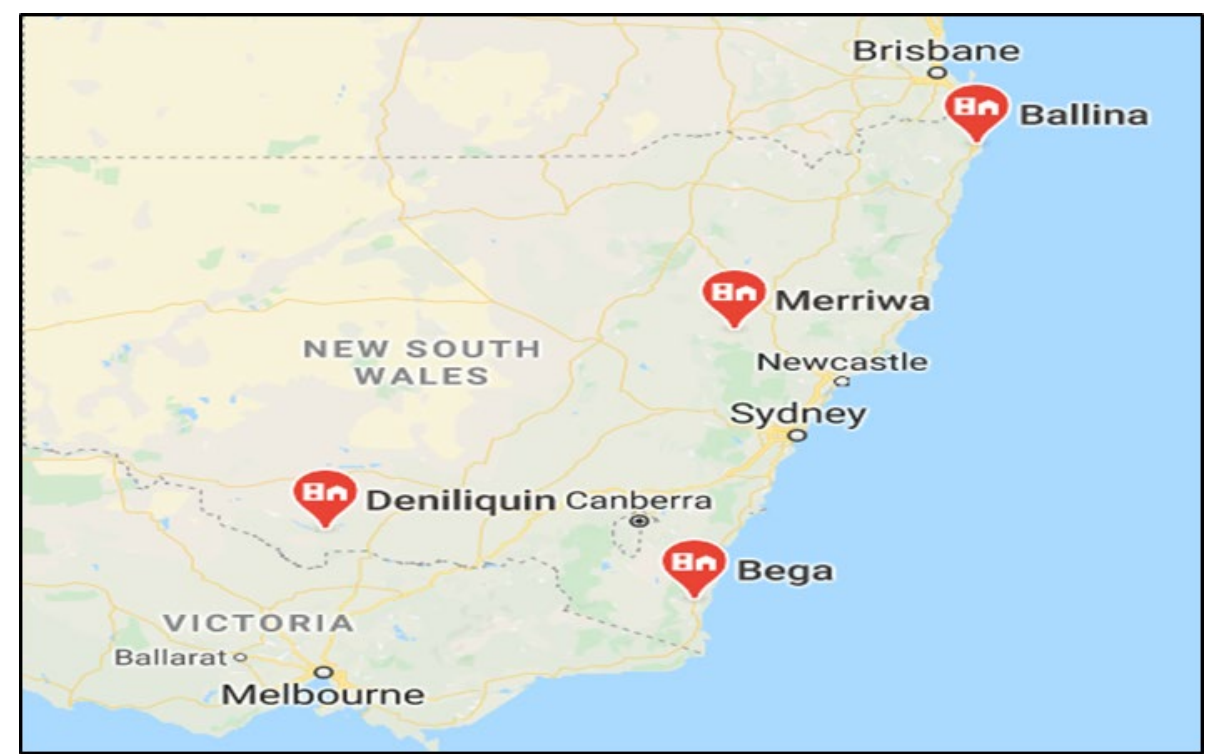

Figure 1. Geographical map of NSW locations of the studied four sites.

Table 1. Geographical coordinates of selected sites

\begin{tabular}{lllll}
\hline \multicolumn{1}{c}{ Station } & & \multicolumn{3}{c}{ Geographical coordinates } \\
\hline Name & ID & Latitude & Longitude & Height \\
\hline Ballina airport AWS & 058198 & -28.8353 & 153.5585 & $1.3 \mathrm{~m}$ \\
\hline Bega AWS & 069139 & -36.6722 & 149.8191 & $41.0 \mathrm{~m}$ \\
\hline Deniliquin airport AWS & 074258 & -35.5575 & 144.9458 & $94.0 \mathrm{~m}$ \\
\hline Merriwa (Roscommon) & 061287 & -32.1852 & 150.1737 & $375.0 \mathrm{~m}$
\end{tabular}

In this study, the hourly wind speed data for four sites in NSW from August 2018 to July 2019 were analyzed. The uncertainties of wind speed measurements are $\pm 10 \%$ for wind speeds greater than $10 \mathrm{~m} / \mathrm{s}$ and $\pm 1 \mathrm{~m} / \mathrm{s}$ for wind speeds at or below $10 \mathrm{~m} / \mathrm{s}$. Based on that measurement, the hourly wind speed data varies with day and from one site to another. In this section, some descriptive statistical values of wind speed, including standard deviation, mean, kurtosis and skewness are discussed. Mean wind speed is the uncomplicated statistical tool and most popularly used method to roughly estimate a specific location's annual energy production, which determines the central tendency of a given time series data. The mean value can be calculated by dividing the sum of the time series of wind data to the number of observations.

The standard deviation offers a clear insight into the wind data dispersion and has a critical significance in wind resource assessment. It gives a clear representation of firstly, how the wind speeds are distributed throughout the period; and secondly, how far the individual wind speeds are from average wind speed. Also, defining the standard deviation for the same mean wind speed, wind turbines can obtain different power outputs depending on the 
157 distribution of wind speed. The standard deviation $\left(\sigma_{U}\right)$ is obtained from the following 158 equations [17]:

$$
\sigma_{U}=\sqrt{\frac{1}{N-1} \sum_{i=1}^{N}\left(U_{i}-\bar{U}\right)^{2}}
$$

160

where $U_{i}$ is the wind speed at $i$ number of observation, $\bar{U}$ is the mean wind speed and $N$ is the number of observations.

Skewness and kurtosis are two common statistical parameters that give insights into the shape of the distribution [18-22]. Skewness is a measure of the symmetry for a dataset distribution around the sample mean [23]. A symmetric distribution will have skewness equal to zero due to the normal distribution having a zero skewness value [24]. The skewness $(s)$ is expressed in the following equation [25]:

$$
S=\frac{1}{N-1}\left(\frac{\sum_{i=1}^{N}\left(U_{i}-\bar{U}\right)^{3}}{\sigma_{U}{ }^{3}}\right)
$$

Kurtosis is a measure of the peakedness of the distribution that measures the combined sizes of the two tails of the distribution [26, 27]. It measures the tail heaviness of distribution when compared to that of normal distribution. The kurtosis of distribution is calculated as [25]:

$$
\text { kurtosis }=\frac{1}{N-1}\left(\frac{\sum_{i=1}^{N}\left(U_{i}-\bar{U}\right)^{4}}{\sigma_{U}{ }^{4}}\right)-3
$$

\subsection{Mathematical models of probability density functions}

This section offers a brief overview of the methodology used for statistical analysis of wind speed variation using four probability density functions.

The probability density function $f(U)$ can be used to determine the number of occurrences of specific wind speeds at a particular site. The probability of wind speed between $u(a)$ and $u(b)$ as explained above is computed as:

$$
f(U)=f\left(U_{a} \leq U \leq U_{b}\right)=\int_{U_{a}}^{U_{b}} f(U) d U
$$

Therefore, it is essential to assess the probability density functions being used to describing wind speed frequency distributions in a different location. The selected stations had various wind speed frequency histograms, permitting flexibility in the analysis of the four probability density functions when describing different wind speed regimes. 
The cumulative distribution function $F(U)$ shows the probability that wind speed is less than or equal to given wind speed. The following equation expressed the cumulative distribution function $F(U)[28]$ :

$$
F\left(U_{i}\right)=\sum_{i=1}^{j} F\left(U_{i}\right)
$$

where $j \leq i$, and $i=1,2,3, \ldots . N$, then the cumulative distribution function calculated as follows:

$$
F\left(U_{i}\right)=\sum_{i=1}^{N} F\left(U_{i}\right)=1
$$

The probability density function $f(U)$ and cumulative distribution function $F(U)$ of four distribution models are expressed using the equation documented in Table 2. Different numerical methods have been used over the last few years for calculating scale and shape factor [29]. The following equation in Table 2 expresses the iterative way that is used in the maximum likelihood algorithm to calculate shape and scale parameters for four listed distribution models.

Table 2. The governing equation of mathematical models of probability density functions.

\section{Weibull distribution}

Probability density function

$$
f(U)=\frac{k}{c}\left(\frac{U}{c}\right)^{k-1} e^{-\left(\frac{U}{c}\right)^{k}}
$$

where $c$ is the scale parameter $(\mathrm{m} / \mathrm{s})$ and $k$ is the shape parameter (dimensionless) [30, 31]

Cumulative distribution function $\quad F(U)$ is calculated as [32]

$$
F(U)=1-\exp \left[-\left(\frac{U}{c}\right)^{k}\right]
$$

Equation parameters

$$
\text { shape and scale parameter [33-35]: }
$$

$$
\begin{aligned}
& k=\left(\frac{\sum_{i=1}^{N} U_{i}^{k} \ln \left(U_{i}\right)}{\sum_{i=1}^{N} U_{i}^{k}}-\frac{\sum_{i=1}^{N} \ln \left(U_{i}\right)}{N}\right)^{-1} \\
& c=\left(\frac{\sum_{i=1}^{N} U_{i}^{k}}{N}\right)^{\frac{1}{k}}
\end{aligned}
$$

\section{Rayleigh distribution}

Probability density function $\quad f(U)=\frac{U}{c^{2}} \exp \left(-\frac{U^{2}}{2 c^{2}}\right)$

where $c$ is scale factor [36-38]

Cumulative distribution function $\quad F(U)=1-\exp \left[-\frac{1}{2}\left(\frac{U}{c}\right)^{2}\right]$

Equation parameter $\quad c=\sqrt{\frac{\sum_{i=1}^{N} U_{i}^{2}}{2 N}}$

\section{Lognormal distribution}


Probability density function $\quad f(U)=\frac{1}{U \alpha \sqrt{2 \pi}} \exp \left[\frac{(\ln (U)-\beta)^{2}}{-2 \alpha^{2}}\right]$

where $\alpha, \beta$ are the shape and scale factors, respectively [39-41]

Cumulative distribution function $\quad F(U)=\frac{1}{2}+\frac{1}{2} \operatorname{erf}\left(\frac{\ln (U)-\beta}{\sqrt{2} \alpha}\right)$

and $\operatorname{erf}(U)$ is the error function which is defined as the following equation [42]:

$\operatorname{erf}(U)=\frac{2}{\sqrt{ } \pi} \int_{0}^{U} \exp \left(-t^{2}\right) d t$

Shape and scale parameters [43]:

$$
\begin{aligned}
& \alpha=\sqrt{\frac{1}{N} \sum_{i=1}^{N}\left[\ln \left(U_{i}\right)-\beta\right]^{2}} \\
& \beta=\frac{\sum_{i=1}^{N} \ln U_{i}}{N}
\end{aligned}
$$

\section{Gamma distribution}

Probability density function

$f(U)=\frac{U^{\xi-1}}{\beta^{\xi} \Gamma(\xi)} \exp \left(-\frac{U}{\beta}\right)$

where $\Gamma$ is the Gamma function, $\xi$ and $\beta$ are shape

parameter and scale parameter, respectively $[44,45]$

Cumulative distribution function

$F(U)=\int \frac{U^{\xi-1}}{\beta^{\xi} \Gamma(\xi)} \exp \left[\frac{-U}{\beta}\right] d U$

shape parameter and scale parameter, respectively, that can be found by solving the following equations

$\beta=\frac{1}{N \xi} \sum_{i=1}^{N}\left(U_{i}\right)$

$\mathrm{N} \ln (\beta)-N \psi(\xi)=\sum_{i=1}^{N} \ln \left(U_{i}\right)$

where $\psi$ is the digamma function, which is calculated using the following equation:

$\psi(\xi)=\frac{d}{d \xi} \ln (\Gamma(\xi))$

\subsection{Evaluation criteria of wind probability density functions}

Four statistical indicators are considered to reflect the superiority of those distribution models to evaluate the accuracy and performance of four distribution models; the root mean square error $(R M S E)$, the coefficient of determination $\left(R^{2}\right)$, Schwarz's Bayesian information criterion $(B I C)$, and Akaike information criterion $(A I C)$. The coefficient of determination $\left(R^{2}\right)$ cannot display the precision of distributions alone; thus, various indicators were used to assess the accuracy. The RMSE calculates the difference between calculated values from the 
probability density function and actual measurement, which is close to zero as much as possible. This indicator is defined as [46]:

$$
R M S E=\sqrt{\frac{1}{N} \sum_{i=1}^{N}\left(X_{\text {observed }}-X_{\text {predicted }}\right)^{2}}
$$

where $X_{\text {observed }}$ is the actual measurement value, $X_{\text {predicted }}$ is the predicted value from probability density function, and $N$ is the observations number.

The coefficient of determination $\left(R^{2}\right)$, which is also called the square of the Pearson correlation coefficient, shows the goodness of fit of different probability density functions. This is done by evaluating the square of the empirical correlation between predicted wind speed and observations values [47]. This parameter can be calculated from [39, 48]:

$$
R^{2}=\frac{\left(\sum_{i=1}^{N}\left(X_{\text {observed }}-\overline{X_{\text {observed }}}\right) \times\left(X_{\text {predicted }}-\overline{X_{\text {predicted }}}\right)\right)^{2}}{\sum_{i=1}^{N}\left(X_{\text {observed }}-\overline{X_{\text {observed }}}\right)^{2} \times \sum_{i=1}^{N}\left(X_{\text {predicted }}-\overline{X_{\text {predicted }}}\right)^{2}}
$$

$A I C$ is the selection criterion employed to compare models that used a maximum likelihood method for estimating the parameters of the probability density functions. AIC is calculated as [49]:

$$
A I C=-2 \log \{p(y \mid \hat{\theta})\}+2 k
$$

where $p(y \mid \hat{\theta})$ is the density of $y$ observed data, $k$ is the number of parameters in the model (dimension $\theta$ ), and $\hat{\theta}$ is the maximum likelihood estimate.

Schwarz's Bayesian information criterion $(B I C)$ is another criterion that serves to compare model selections [50]. It is more complicated than $(A I C)$ selection, since BIC is essentially an attempt to distinguish the true model. This BIC is asymptotically consistent with choosing the model in contrast to the $(A I C)$ criterion, which is not asymptotically consistent. Schwarz's Bayesian information criterion $(B I C)$ is expressed as [49]:

$$
B I C=-2 \log \{p(y \mid \hat{\theta})\}+k \log (n)
$$

\subsection{Wind direction}

For developing a successful wind farm, a state-of-the-art wind speed and direction measuring system is necessary to identify the suitable candidate site. In addition, to measure mean wind speed, wind direction estimation wields crucial importance for both wind assessment and wind turbine control system [51]. The frequency distribution of wind direction 
can be displayed in a polar form, which is known as a wind rose [52]. The wind rose plots divide each segment of the polar plot in colors to display the time percentage at which the wind is blowing in a certain speed range [53]. The wind can be plotted by dividing wind sample data into several divisions, such as 12 or 16 and calculating the statistical share of each sector. Finding the overall wind direction and frequency by applying the wind rose diagram is important for specifying the position of wind farm constructions [54].

\subsection{Power law and surface roughness and wind power density}

Most of the wind measuring devices are installed at an elevation of $10 \mathrm{~m}$, and any rise in elevation influences a wind speed to a specific height level. Topographical features such as hills and mountaintops also greatly affect wind speed. The wind speed reduces remarkably on the lee side while it increases on the top or luff side of a mountain, which is perpendicular to the wind flow. Thus, wind speed increases with elevation as the speed is decreased by the roughness of the terrain [55]. The most common expression is used to calculate wind speeds with varying elevation, and this is known as the power-law [56, 57]. The power-law adjusts the observed wind speed according to different heights using the following equation [58]:

$$
\frac{U_{y}}{U_{0}}=\left(\frac{h_{y}}{h_{0}}\right)^{\alpha}
$$

where $h_{0}$ is the reference height, $h_{y}$ is the desired height, $U_{y}$ and $U_{0}$ are wind speeds at $h_{y}$ and $h_{0}$, respectively, and $\alpha$ is the power exponent relying on different factors. These include such things as atmospheric stability, surface roughness and nature of the terrain. Numerically, the power exponent varies between 0.05 and 0.5 , with the most frequently used value being $1 / 7$ because it is suitable for sites having neutral stability [32, 59].

One of the most important indicators that are used to classify a capacity of wind resources in a specific location is called wind power density. It is expressed in the following equation [60]:

$$
P D=\int_{0}^{\infty} \frac{1}{2} \rho U^{3} f(U) d U
$$

where $P D$ is the wind power density $\left(\mathrm{W} / \mathrm{m}^{2}\right), \rho$ is the air density $\left(\mathrm{kg} / \mathrm{m}^{3}\right)$, and $f(U)$ is the probability density function.

\section{Results and discussion}

\subsection{Analysis of descriptive statistical values of wind data}


Based on that measurement, the hourly wind speed varies with day and from one site to

261 another. It is easier to study the monthly mean and maximum wind speed for selected locations,

262 as shown in Figure 2(a, b). Ballina and Merriwa exhibited the highest mean values in February

2632019 , and their highest mean values were $5.009316 \mathrm{~m} / \mathrm{s}, 4.892304 \mathrm{~m} / \mathrm{s}$, respectively. The

264 maximum wind speed for Ballina was recorded in February, which is equal to $12.80556 \mathrm{~m} / \mathrm{s}$,

265 while the maximum wind speed at Merriwa was achieved in December, which is equal to

$26613.36111 \mathrm{~m} / \mathrm{s}$. Bega and Deniliquin exhibited the highest mean wind speed values in November

2672018.
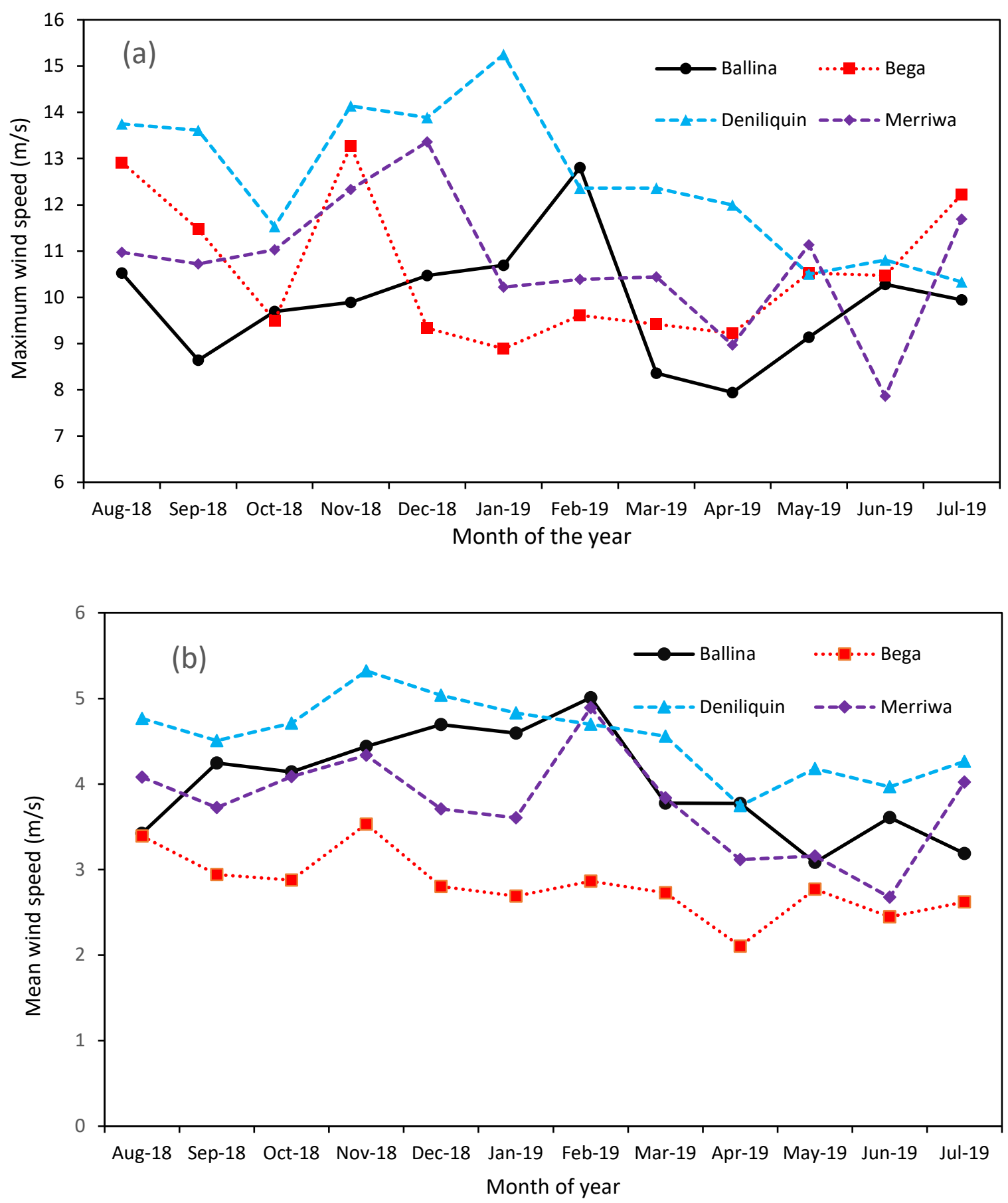

Figure 2. Monthly maximum (a) and mean (b) wind speeds at four sites in NSW, Australia. 
Some significant statistics values, including yearly maximum, mean, median, standard

272 deviation, skewness, and kurtosis, are presented in Table 3. For the four sites, the mean wind speed values vary from 2.81 to $4.53 \mathrm{~m} / \mathrm{s}$. The standard deviation has a value between 2.134 and 2.288. Skewness has a value between 0.281617 and 0.914067 , while kurtosis is between 2.759042 and 3.522561. The descriptive statistical parameters of the measured wind speed data at five stations in the east and southeast of Iran had been evaluated by Alavi et al. [61]. In their study, the skewness values varied between 0.24 and 1.22, and kurtosis values varied between 2.16 and 3.59 .

Table 3. Descriptive statistical parameters of the measured wind speed data for selected stations.

\begin{tabular}{lcccccc}
\hline & $\begin{array}{c}\text { Maximum } \\
(\mathrm{m} / \mathrm{s})\end{array}$ & $\begin{array}{c}\text { Mean } \\
(\mathrm{m} / \mathrm{s})\end{array}$ & $\begin{array}{c}\text { Median } \\
(\mathrm{m} / \mathrm{s})\end{array}$ & $\begin{array}{c}\text { Standard } \\
\text { deviation }(\mathrm{m} / \mathrm{s})\end{array}$ & Skewness & Kurtosis \\
\hline Ballina & 12.806 & 3.945 & 3.833 & 2.134 & 0.281617 & 2.759042 \\
Bega & 13.278 & 2.810 & 2.222 & 2.288 & 0.914067 & 3.347564 \\
Deniliquin & 15.250 & 4.530 & 4.111 & 2.211 & 0.687683 & 3.522561 \\
Merriwa & 13.361 & 3.745 & 3.306 & 2.157 & 0.747539 & 3.199951
\end{tabular}

\subsection{Analysis of probability distribution functions}

The wind speed values continuously vary with time. The measured wind speed data in a specific duration of time can be studied using statistical analysis to get the required information about the frequency of wind distribution. Various probability distribution functions can show the wind speed frequency curve. The Rayleigh, Weibull, Gamma, and Lognormal are the most popular probability distribution functions which will be used in this paper for wind speed analysis. Graphical representation of the listed four probability distribution functions at the four sites in NSW are presented in Figure 3(a-d). This figure shows the comparison between observed data and fitting functions using Rayleigh, Weibull, Gamma, and Lognormal distribution to get an idea about which probability functions give the best fitting wind speed data. Also, Figure 4(a-d) presents the fitted cumulative distribution function plots with a measured wind speed curve for all stations. The cumulative distribution function shows the probability that wind speed is less than or equal to given wind speed. 

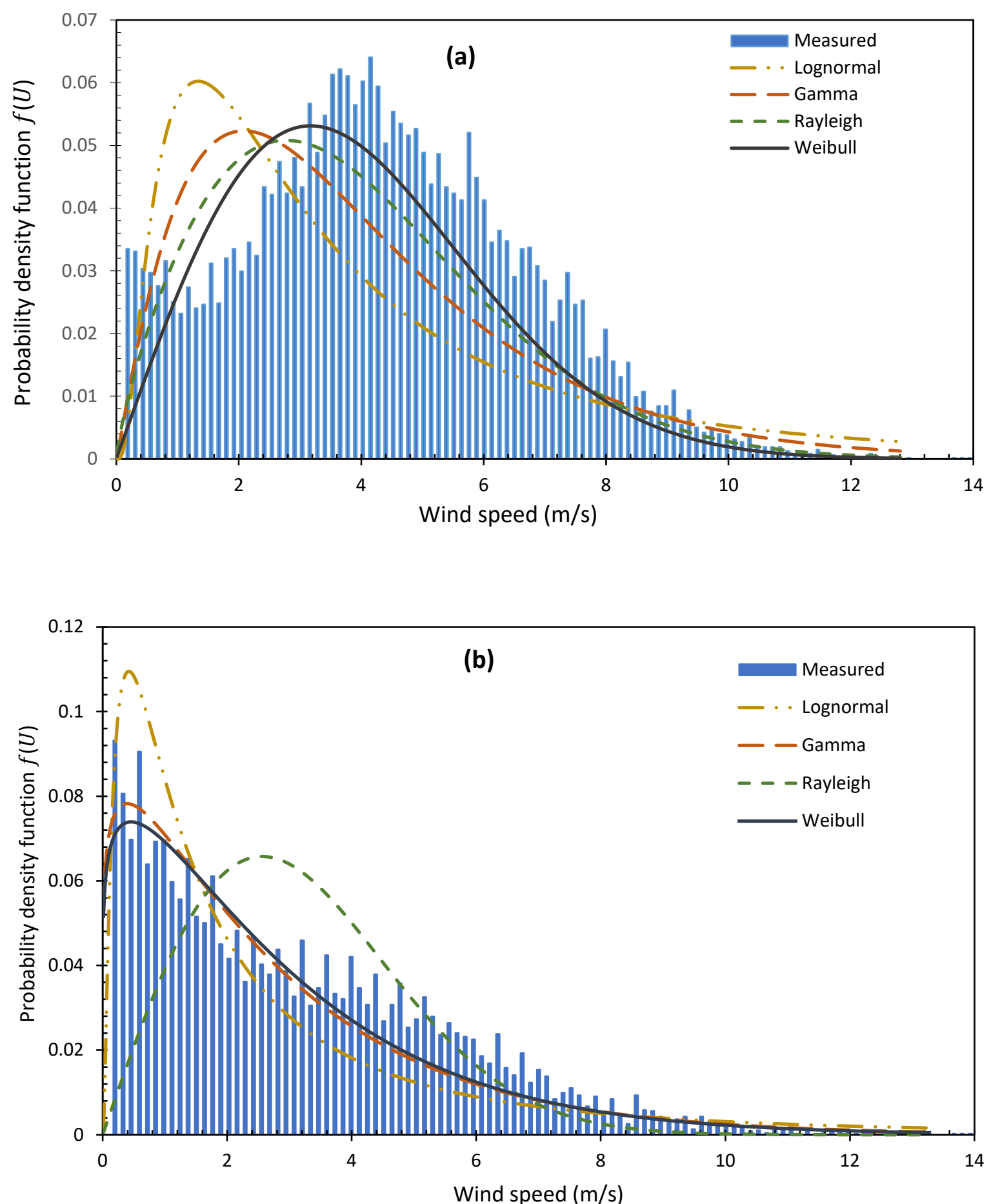

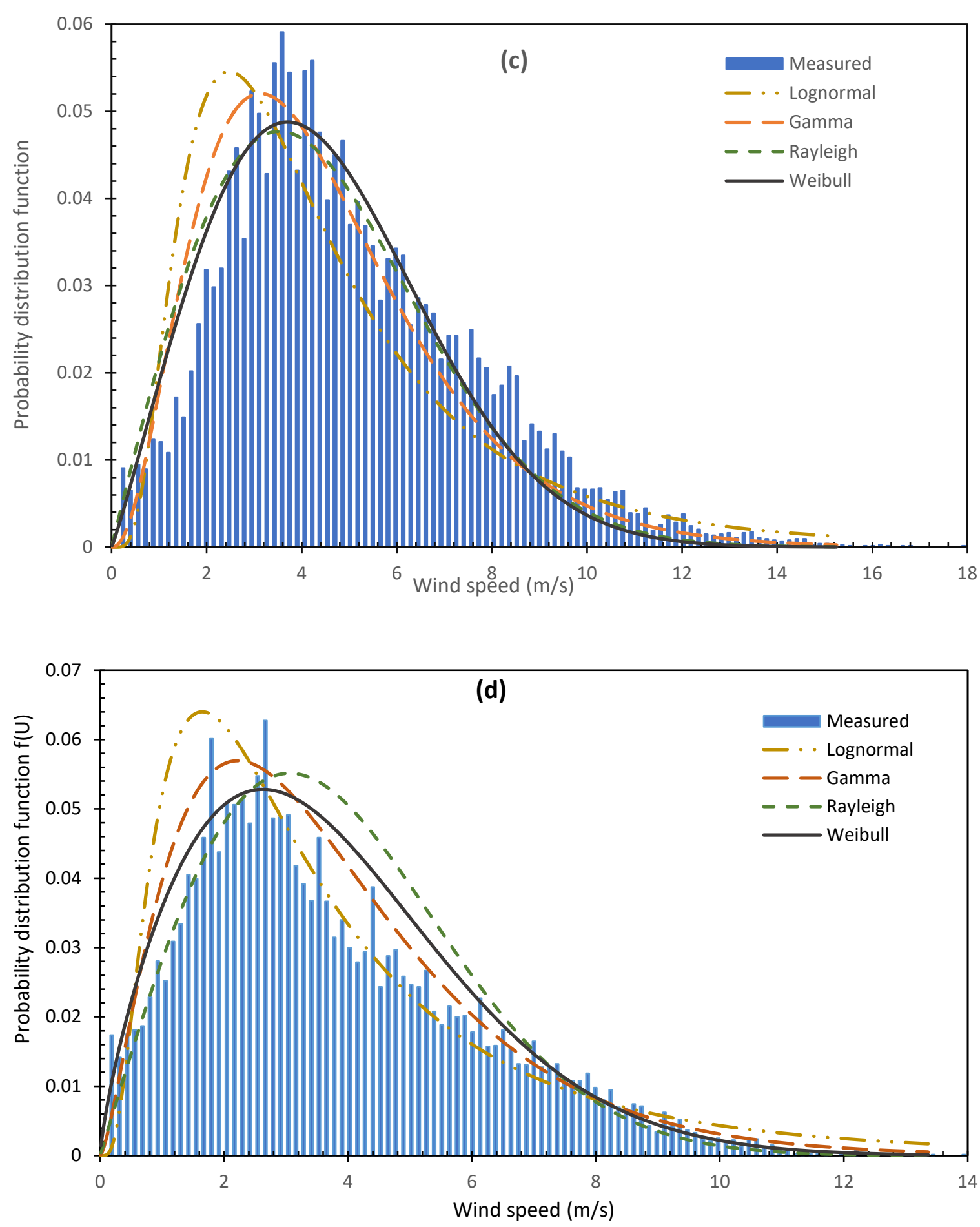

Figure 3. Probability density function at the following locations: (a). Ballina, (b). Bega, (c). 

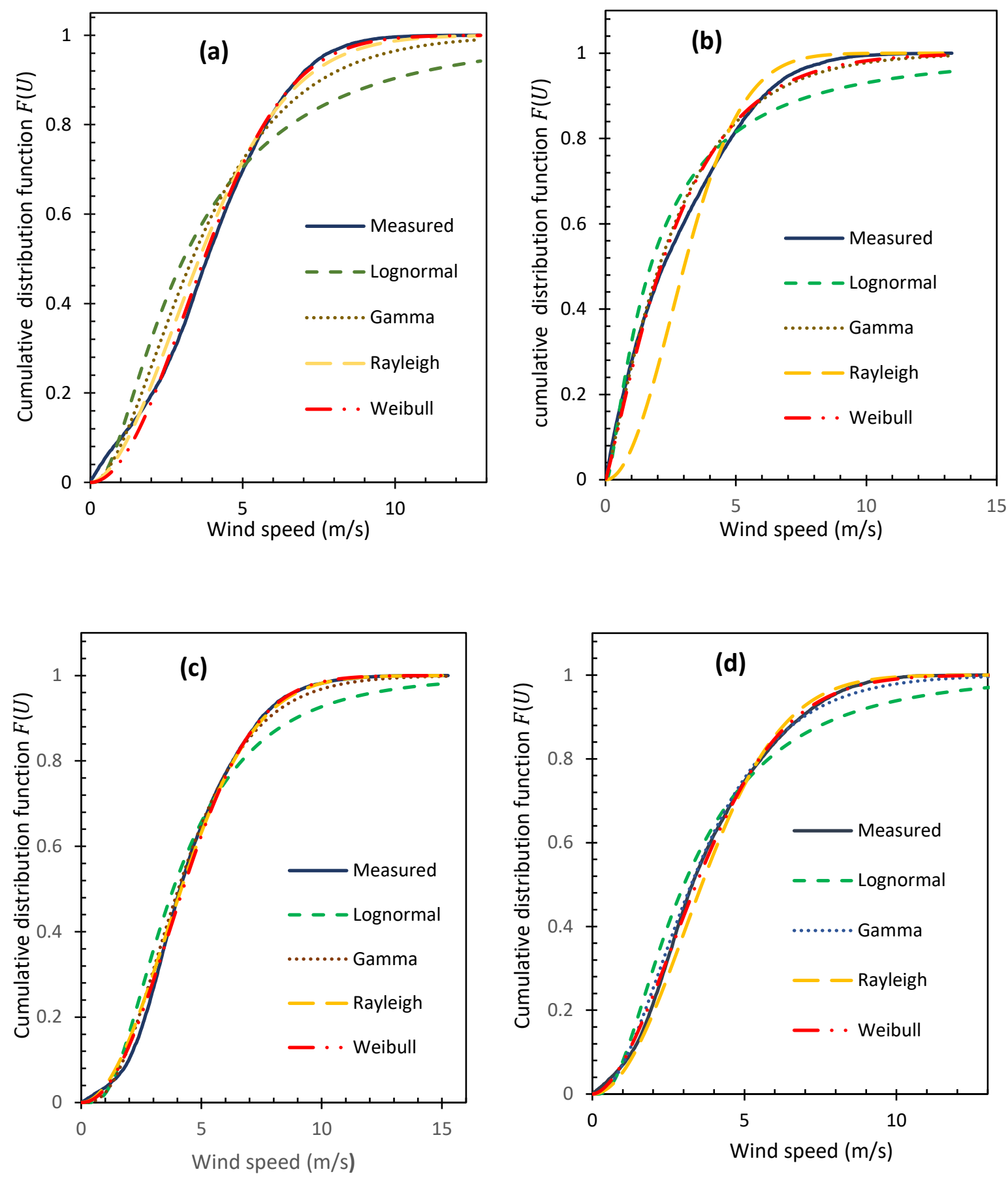

Figure 4. Cumulative distribution functions at Ballina (a), Bega (b), Deniliquin (c) and Merriwa (d).

Table 4 compares the goodness of fit for different probability density functions concerning the selected sites. The most popular statistical indicators are $R^{2}$ and $R M S E$, which test the goodness of fit. Larger $R^{2}$ values give better goodness of fit, while smaller $R M S E$ values indicate a better fit. It can be seen from Table 4 that the $R^{2}$ values range from 0.905673 to 0.99899 , which indicates that the matching between probability distribution functions and the recorded data is very high, while the $R M S E$ varies between 0.010771 and 0.094731 . Weibull is the most accurate distribution according to $R^{2}$ and RMSE. RMSE variation is between 
0.010771 and 0.022187 , which are still lower when compared with other distributions.

$311 R^{2}$ varies slightly between 0.993604 and 0.998999 , and those values are recorded at Bega and 312 Merriwa.

313

314

For Ballina and Deniliquin, the Weibull distribution is the most accurate, followed by Rayleigh distribution, which can also be noticed from probability density function and cumulative distribution function when compared to measured data. For Bega and Merriwa, the best fitting distribution for measured data is the Weibull distribution followed by Gamma distribution. Therefore the lognormal distribution is the least accurate distribution used at the four sites. The outcome of this study agreed with Tar [62] who investigated lognormal, Weibull, and Gamma distribution for seven Hungarian meteorological stations. The outcomes showed the good accuracy of Weibull distribution and the shape and scale parameters of monthly average speeds at different altitudes of $20,40,60,80$, and $100 \mathrm{~m}$ were calculated.

Table 4. Comparison of the goodness of fit between different distribution functions using statistical indicators.

\begin{tabular}{llccccc}
\hline \multirow{2}{*}{ Ballina } & & $R^{2}$ & RMSE & AIC & BIC & Rank \\
\cline { 3 - 7 } & & & & & & \\
& Lognormal & 0.905673 & 0.092157 & 2.24974 & 10.207512 & 4 \\
& Gamma & 0.976339 & 0.050062 & 2.49842 & 10.456191 & 3 \\
& Rayleigh & 0.99377 & 0.027025 & -1.517715 & 6.440057 & 2 \\
& Weibull & 0.997073 & 0.019247 & -0.870346 & 7.087426 & 1 \\
\hline \multirow{5}{*}{ Bega } & & & & & & \\
\hline \multirow{5}{*}{ Deniliquin } & Lognormal & 0.944095 & 0.058708 & 2.795589 & 10.783512 & 3 \\
& Gamma & 0.991548 & 0.025016 & 3.697678 & 11.685601 & 2 \\
& Rayleigh & 0.931653 & 0.094731 & -0.44371 & 7.544213 & 4 \\
& Weibull & 0.993604 & 0.022187 & -0.715431 & 7.272492 & 1 \\
& Lognormal & 0.978405 & 0.049123 & 2.071796 & 10.321163 & 4 \\
& Gamma & 0.997253 & 0.018551 & 1.599114 & 9.848481 & 3 \\
& Rayleigh & 0.997661 & 0.017197 & -1.085798 & 7.163568 & 2 \\
& Weibull & 0.998587 & 0.013567 & -1.797523 & 6.451844 & 1 \\
\hline \multirow{6}{*}{ Merriwa } & & & & & & \\
\hline
\end{tabular}


Figure 5(a) illustrates the comparison between the calculated skewness values from the different employed distribution functions with the measured data for the four sites. Meanwhile,

327 Figure 5(b) depicts the comparison of the kurtosis values. As shown in Figure 5(a), the Weibull distribution gives the nearby values of the skewness when compared with the skewness of recorded data at Ballina and Bega. In Merriwa and Deniliquin the Gamma distribution gives the closest values of skewness when compared to the value of skewness from measured data. It is also observed from Figure 5(b) that the kurtosis values from Gamma distribution are the closest values for the measured kurtosis values at Ballina and Merriwa.
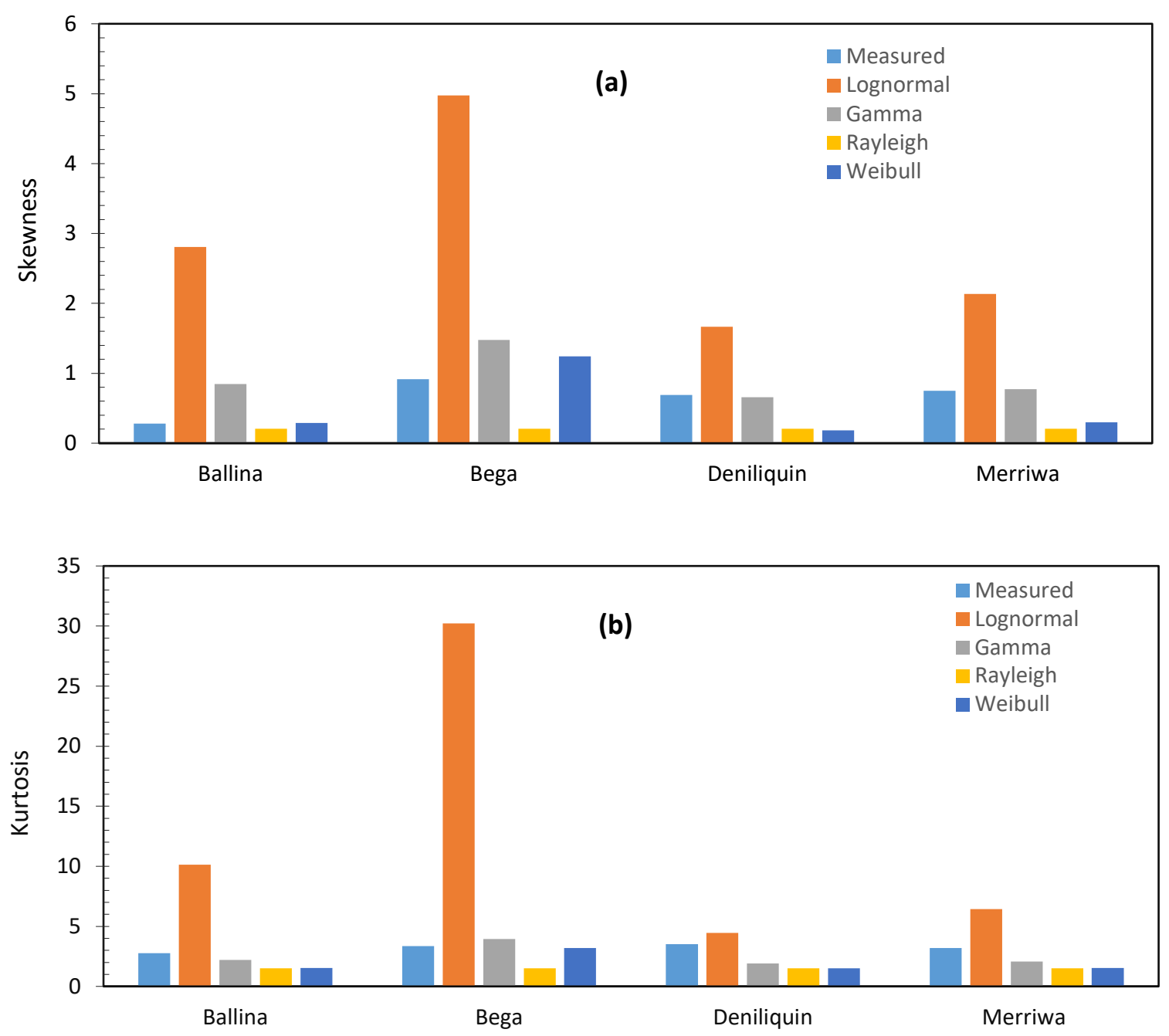

Figure 5. Comparison of skewness (a) and kurtosis (b) values of different distribution functions.

The Weibull function is the optimal function according to the wind analysis results for the four sites. According to $R^{2}$ and $R M S E$, the Weibull function - as previously discussed matches well with measured data. The results of this study agree with Togrul and Ertekin finding [63] who used Weibull function to determine the wind power potential at seven sites in Turkey. 
It is therefore essential to investigate the Weibull parameters to find the wind profiles of selected sites. Table 5 tabulates the annual two Weibull parameters, scale parameter $c(\mathrm{~m} / \mathrm{s})$, and shape parameter $k$ (dimensionless) for selected regions. It is seen from the table that the scale parameter varies between $2.935 \mathrm{~m} / \mathrm{s}$ and $5.042 \mathrm{~m} / \mathrm{s}$, the shape parameter ranges from 1.137 to 2.096 where the maximum value of shape and scale factors is related to Deniliquin. In contrast, the minimum value of shape and scale factors is related to Bega. The $k$ parameter has less variation than the scale parameter.

Table 5. Annual Weibull parameters for the selected sites.

\begin{tabular}{lcc}
\hline & $\begin{array}{c}\text { shape parameter } k \\
\text { (dimensionless) }\end{array}$ & $\begin{array}{c}\text { scale parameter } c \\
(\mathrm{~m} / \mathrm{s})\end{array}$ \\
\hline Ballina & 1.787 & 4.384 \\
Bega & 1.137 & 2.935 \\
Deniliquin & 2.096 & 5.042 \\
Merriwa & 1.771 & 4.197 \\
\hline
\end{tabular}

\subsection{Wind direction}

The determination of wind direction is an essential step in the assessment of wind energy when using it properly. The wind rose diagram is used to display the wind speed frequency and corresponding wind directions. Figure 6(a-d) indicates the wind rose diagrams for selected sites. The polar wind figures consist of 12 sectors, each arc covering $30^{\circ}$.

The direction percentages of different wind speeds are plotted in these diagrams. For Ballina, it is noted that the highest wind speed frequency $(7 \%)$ occurs in the sector between $240^{\circ}$ to $270^{\circ}$. The most wind originates in the sectors from the $180^{\circ}-240^{\circ}$ and $30^{\circ}-60^{\circ}$ for Bega, while the dominant wind speed frequency is above $(6 \%)$ at $180^{\circ}-210^{\circ}$. For Deniliquin, the wind direction is more evenly distributed when compared to other sites, with a majority of wind movement occurring in the sector between $210^{\circ}$ to $300^{\circ}$. The sector of $210^{\circ}-240^{\circ}$ has the highest frequency value, which is around 5\%. For Merriwa, the dominating wind is in the areas $90^{\circ}-120^{\circ}$ and $270^{\circ}-300^{\circ}$, while the maximum frequency above $10 \%$ is achieved in sector $90^{\circ}-120^{\circ}$. From the wind rose for four sites, it was evident that the dominant wind direction varied from one place to another. This result agreed with the finding of Allouhi et al. [64] for Laayoune, Tetouane, Hoceima, Assila, Essouira, and Dakhla in Morocco. They documented a diverse prevailing wind direction for the investigated sites. 

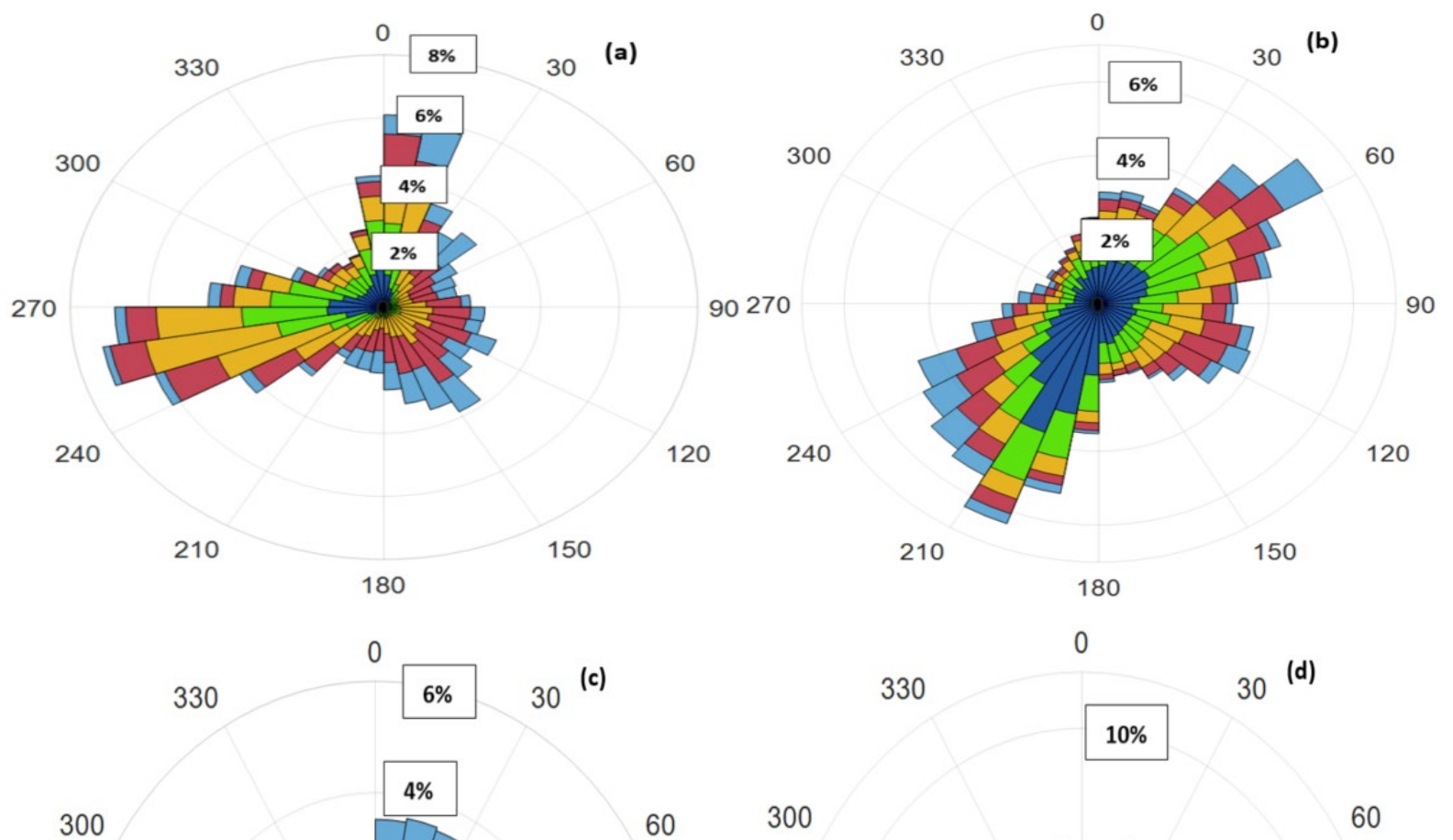

60

300

60
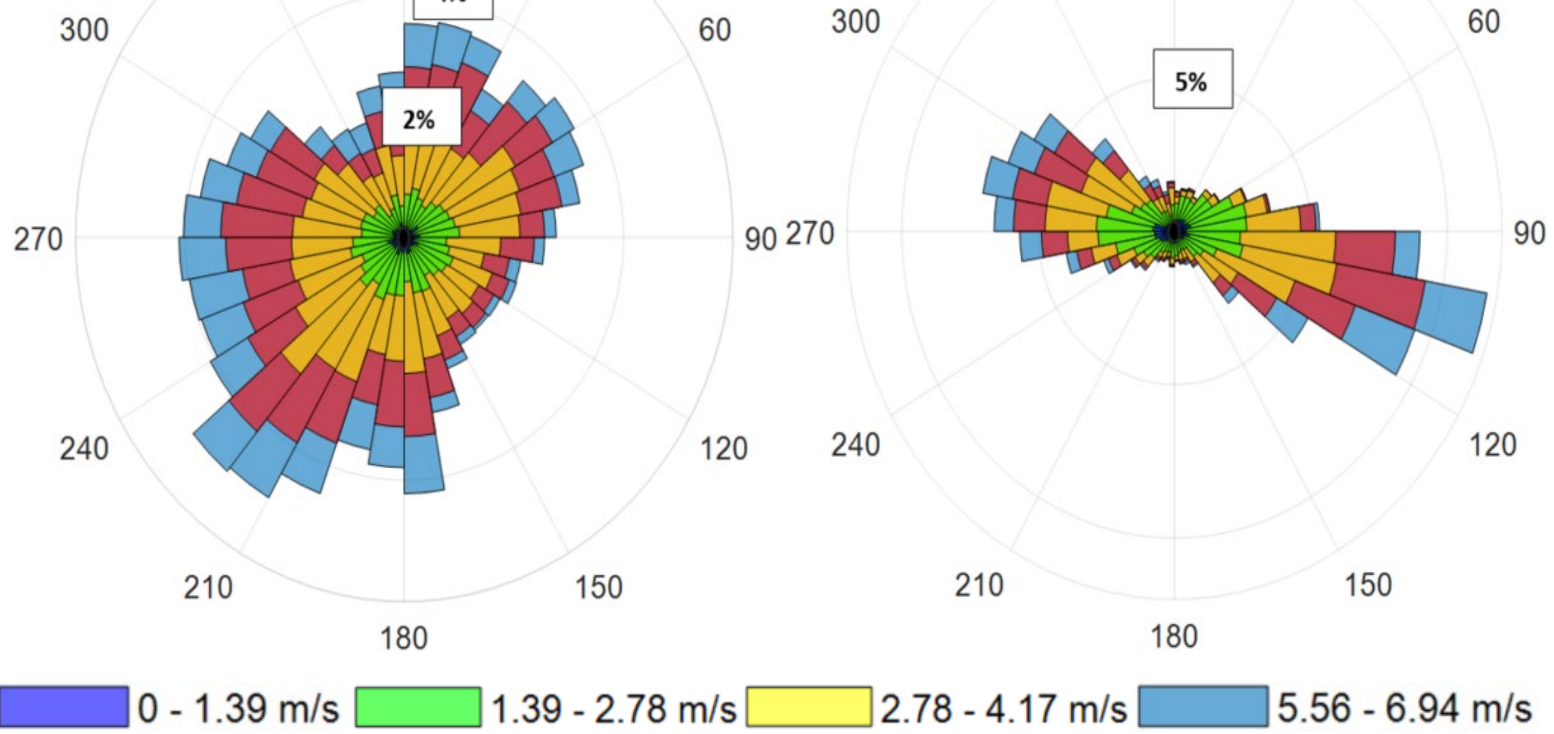

Figure 6. Wind rose of wind data collected from the following sites at (a) Ballina, (b) Bega,

\subsection{Wind power density}

As discussed previously, Weibull distribution is the most accurate distribution function used in this analysis; this explained that the wind power density would be calculated in equation (28) depending on the shape and scale parameters of the Weibull method. As illustrated in Table 6, the annual mean power density at selected sites varies from 85.677 to $202.747 \mathrm{~W} / \mathrm{m}^{2}$ at $50 \mathrm{~m}$ elevation; this difference leads to a change of mean wind speed from one location to another. Thus the power density has a relationship that is proportional to the cube of the wind speed, which explains that Bega has a mean wind speed of $2.810 \mathrm{~m} / \mathrm{s}$ and the lowest wind power 
density at $42.954 \mathrm{~W} / \mathrm{m}^{2}$ at $10 \mathrm{~m}$ elevation. In comparison, Deniliquin has a mean wind speed of $4.530 \mathrm{~m} / \mathrm{s}$ and the highest power density of $108.618 \mathrm{~W} / \mathrm{m}^{2}$ at the same altitude. Also, the increase in elevation plays a role in rising wind speed and power density. This is clear when comparing wind power density for Ballina and Merriwa, which had a mean wind speed at an elevation of $10 \mathrm{~m} 3.945 \mathrm{~m} / \mathrm{s}$ and $3.745 \mathrm{~m} / \mathrm{s}$, respectively. The differences in mean wind speed at those sites are quite small, while the difference of wind power density is very slight at an elevation of $10 \mathrm{~m}$. However, when increasing the elevation to $50 \mathrm{~m}$, the differences between power densities are more prominent.

Table 6. Power density with $10 \mathrm{~m}, \mathbf{4 0} \mathrm{m}$, and $50 \mathrm{~m}$ elevation for selected sites

\begin{tabular}{cccc}
\hline & $10 \mathrm{~m}$ & $40 \mathrm{~m}$ & $50 \mathrm{~m}$ \\
\hline Site & Wind power density & Wind power density & Wind power density \\
& $\left(\mathrm{W} / \mathrm{m}^{2}\right)$ & $\left(\mathrm{W} / \mathrm{m}^{2}\right)$ & $\left(\mathrm{W} / \mathrm{m}^{2}\right)$ \\
\hline Ballina & 65.618 & 118.933 & 130.882 \\
Bega & 42.954 & 77.855 & 85.677 \\
Deniliquin & 108.618 & 184.247 & 202.747 \\
Merriwa & 62.412 & 113.123 & 124.487 \\
\hline
\end{tabular}

391

According to Table 7, when classifying the sites according to wind power density, Ballina, Bega, and Merriwa are classified as class 1, so the wind speed at those places is not enough to generate a wind speed for large scale wind generation application [3]. However, it could be used for a remote small electricity generation, agricultural activities, and water pumping. Deniliquin is classified as class 2, and this means it is a marginal wind resource site.

Table 7. Classification of wind class accordingly to wind speed and wind power density

\begin{tabular}{ccccc}
\hline \multirow{2}{*}{$\begin{array}{c}\text { Wind } \\
\text { class }\end{array}$} & $\begin{array}{c}\text { Wind power density } \\
\left(\mathrm{W} / \mathrm{m}^{2}\right)\end{array}$ & $\begin{array}{c}\text { Wind speed } \\
(\mathrm{m} / \mathrm{s})\end{array}$ & $\begin{array}{c}\text { Wind power density } \\
\left(\mathrm{W} / \mathrm{m}^{2}\right)\end{array}$ & $\begin{array}{c}\text { Wind speed } \\
(\mathrm{m} / \mathrm{s})\end{array}$ \\
\hline 1 & $<100$ & $<4.4$ & $<200$ & $<5.6$ \\
\hline 2 & $<150$ & $<5.1$ & $<300$ & $<6.4$ \\
\hline 3 & $<200$ & $<5.6$ & $<400$ & $<7.0$ \\
\hline 4 & $<250$ & $<6.0$ & $<500$ & $<7.5$ \\
\hline 5 & $<300$ & $<6.4$ & $<600$ & $<8.0$ \\
\hline
\end{tabular}




\begin{tabular}{ccccc}
\hline 6 & $<400$ & $<7.0$ & $<800$ & $<8.8$ \\
\hline 7 & $<1000$ & $<9.4$ & $<2000$ & $<11.9$
\end{tabular}

\section{Conclusions}

400

401

402

403

404

405

406

407

408

409

410

411

412

413

414

415

416

417

Few studies have investigated the wind speed characteristics and wind power potentials in NSW, which could be used for future prediction of wind applications. Therefore, this study investigated the wind speed characteristics and the wind energy potential in four selected locations in NSW, Australia. The objective is to give an in-depth statistical assessment based on statistical indicators for different probability density functions. The results can be summarized as follows:

1. The maximum wind speed at Ballina $(12.81 \mathrm{~m} / \mathrm{s})$ was recorded in February, and the maximum wind speed at Merriwa $(13.36 \mathrm{~m} / \mathrm{s})$ was achieved in December. Bega and Deniliquin recorded the highest mean wind speed values in November 2018.

2. Weibull function is the most proper distribution based on indicators of $\mathrm{R}^{2}$ and $R M S E$. The RMSE varied between 0.010771 and 0.022187 , which is lower when compared with other distributions. Meanwhile $R^{2}$ varied in a narrow range between 0.993604 and 0.998999 at Bega and Merriwa.

3. The mean wind speed of the selected regions varied from 2.81 to $4.53 \mathrm{~m} / \mathrm{s}$ at the elevation of $10 \mathrm{~m}$. The wind power density was between $42.95-108.62 \mathrm{~W} / \mathrm{m}^{2}$ at $10 \mathrm{~m}$ elevation and between $85.68-202.75 \mathrm{~W} / \mathrm{m}^{2}$ at a $50 \mathrm{~m}$ elevation. Thus the maximum wind power density was documented for Deniliquin with a wind class of 2 , which showed it is a marginal wind speed resource. Meanwhile Ballina, Bega and Merriwa had a wind class of 1 which means they were categorized as a poor wind resource.

The statistical analysis results show that the highest wind potential was at Deniliquin, with Weibull shape and scale parameters of 2.096 and $5.042 \mathrm{~m} / \mathrm{s}$, respectively. These results encourage the utilization of small-scale wind energy projects in this area. For future works, the feasibility for using wind energy for supplied electrical applications in rural areas in Deniliquin could be a useful research direction

\section{Nomenclature}

ID Station number

$\sigma_{U} \quad$ Standard deviation $(\mathrm{m} / \mathrm{s})$

$S \quad$ Skewness

$f(U) \quad$ Probability density function 
$F(U) \quad$ Cumulative distribution function

$430 \quad R^{2} \quad$ Coefficient of determination

431 RMSE The root mean square error

432 BIC Schwarz's Bayesian information criterion

433 AIC Akaike information criterion

$434 \quad P D \quad$ The wind power density $\left(\mathrm{W} / \mathrm{m}^{2}\right)$

$435 \quad k \quad$ Shape parameter (dimensionless)

$436 \quad c \quad$ Scale parameter $(\mathrm{m} / \mathrm{s})$

\section{Acknowledgements}

The authors would like to acknowledge the Australian Government Bureau of

Meteorology for supplying wind data.

440

441

442

443

444

445

446

447

448

449

450

451

452

453

454

455

456

457

458

459

460

461

462

463

464

465

466

467

468

469

470

471

472

473

474

475

476

\section{Reference}

[1] Department of the Environment and Energy, Australian Government. Australian Energy Update 2018. (August 2018).

[2] Z. Shu, Q. Li, P. Chan. Statistical analysis of wind characteristics and wind energy potential in Hong Kong. Energy Conversion and Management. 101 (2015) 644-57.

[3] M. Irwanto, N. Gomesh, M. Mamat, Y. Yusoff. Assessment of wind power generation potential in Perlis, Malaysia. Renewable and sustainable energy reviews. 38 (2014) 296-308.

[4] I. Janajreh, L. Su, F. Alan. Wind energy assessment: Masdar City case study. Renewable energy. 52 (2013) 8-15.

[5] A. Teimourian, A. Bahrami, H. Teimourian, M. Vala, A. Oraj Huseyniklioglu. Assessment of wind energy potential in the southeastern province of Iran. Energy Sources, Part A: Recovery, Utilization, and Environmental Effects. 42 (2020) 329-43.

[6] A. Mezidi, O. Guerri, S.M. Boudia, K. Mohammedi. Influence of wind data temporal variation in wind resource assessment. Two case studies in the southern part of Algeria. Energy Sources, Part A: Recovery, Utilization, and Environmental Effects. 42 (2020) 161-75.

[7] C. Ozay, M.S. Celiktas. Statistical analysis of wind speed using two-parameter Weibull distribution in Alaçatı region. Energy Conversion and Management. 121 (2016) 49-54.

[8] P.A.C. Rocha, R.C. de Sousa, C.F. de Andrade, M.E.V. da Silva. Comparison of seven numerical methods for determining Weibull parameters for wind energy generation in the northeast region of Brazil. Applied Energy. 89 (2012) 395-400.

[9] D. Solyali, M. Altunç, S. Tolun, Z. Aslan. Wind resource assessment of Northern Cyprus. Renewable and Sustainable Energy Reviews. 55 (2016) 180-7.

[10] O. Guerri, A. Dali, S.M. Boudia, N. Yassaa. Performance evaluation of a wind farm using different power density distributions. Energy Sources, Part A: Recovery, Utilization, and Environmental Effects. (2020) 1-13.

[11] N. Khlaifat, A. Altaee, J. Zhou, Y. Huang, A. Braytee. Optimization of a Small Wind Turbine for a Rural Area: A Case Study of Deniliquin, New South Wales, Australia. Energies. 13 (2020) 2292.

[12] V.T. Morgan. Statistical distributions of wind parameters at Sydney, Australia. Renewable Energy. 6 (1995) 39-47.

[13] Y.A. Katsigiannis, G.S. Stavrakakis. Estimation of wind energy production in various sites in Australia for different wind turbine classes: A comparative technical and economic assessment. Renewable energy. 67 (2014) 230-6.

[14] D. Maunsell, T. Lyons, J. Whale. Wind resource assessment of a site in Western Australia. (2004).

[15] D. Mills. Assessing the potential contribution of renewable energy to electricity supply in Australia: A study of renewable energy with a particular focus upon domestic rooftop photovoltaics, domestic solar hot water and commercial wind energy. (2001). 
[16] W. Hallgren, U.B. Gunturu, A. Schlosser. The potential wind power resource in Australia: a new perspective. PloS one. 9 (2014) e99608.

[17] M. Gökçek, A. Bayülken, Ş. Bekdemir. Investigation of wind characteristics and wind energy potential in Kirklareli, Turkey. Renewable Energy. 32 (2007) 1739-52.

[18] H. MacGillivray, K. Balanda. The relationships between skewness and kurtosis. Australian Journal of Statistics. 30 (1988) 319-37.

[19] K.V. Mardia. Measures of multivariate skewness and kurtosis with applications. Biometrika. 57 (1970) 519-30.

[20] J. Bai, S. Ng. Tests for Skewness, Kurtosis, and Normality for Time Series Data. Journal of Business \& Economic Statistics. 23 (2005) 49-60.

[21] D. Joanes, C. Gill. Comparing measures of sample skewness and kurtosis. Journal of the Royal Statistical Society: Series D (The Statistician). 47 (1998) 183-9.

489 [22] B. Sürücü. Goodness-of-fit tests for multivariate distributions. Communications in Statistics-

Theory and Methods. 35 (2006) 1319-31.

[23] M.S. Srivastava. A measure of skewness and kurtosis and a graphical method for assessing multivariate normality. Statistics \& Probability Letters. 2 (1984) 263-7.

[24] G. Brys, M. Hubert, A. Struyf. A robust measure of skewness. Journal of Computational and Graphical Statistics. 13 (2004) 996-1017.

[25] J. Wang, J. Hu, K. Ma. Wind speed probability distribution estimation and wind energy assessment. Renewable and sustainable energy Reviews. 60 (2016) 881-99.

[26] K.P. Balanda, H. MacGillivray. Kurtosis: a critical review. The American Statistician. 42 (1988) 111-9.

[27] G. Brys, M. Hubert, A. Struyf. Robust measures of tail weight. Computational statistics \& data analysis. 50 (2006) 733-59.

[28] A.N. Celik. Energy output estimation for small-scale wind power generators using Weibullrepresentative wind data. Journal of wind engineering and industrial aerodynamics. 91 (2003) 693707.

[29] K. Bury. Statistical distributions in engineering. Cambridge University Press1999.

[30] F. Fazelpour, N. Soltani, S. Soltani, M.A. Rosen. Assessment of wind energy potential and economics in the north-western Iranian cities of Tabriz and Ardabil. Renewable and Sustainable Energy Reviews. 45 (2015) 87-99.

[31] J.F. Manwell, J.G. McGowan, A.L. Rogers. Wind energy explained: theory, design and application. John Wiley \& Sons2010.

[32] J. Kamau, R. Kinyua, J. Gathua. 6 years of wind data for Marsabit, Kenya average over 14 m/s at $100 \mathrm{~m}$ hub height; An analysis of the wind energy potential. Renewable Energy. 35 (2010) 1298-302. [33] J.V. Seguro, T.W. Lambert. Modern estimation of the parameters of the Weibull wind speed distribution for wind energy analysis. Journal of Wind Engineering and Industrial Aerodynamics. 85 (2000) 75-84.

[34] P.A. Costa Rocha, R.C. de Sousa, C.F. de Andrade, M.E.V. Da Silva. Comparison of seven numerical methods for determining Weibull parameters for wind energy generation in the northeast region of Brazil. Applied Energy. 89 (2012) 395-400.

[35] M. Stevens, P. Smulders. The estimation of the parameters of the Weibull wind speed distribution for wind energy utilization purposes. Wind engineering. (1979) 132-45.

[36] S.F. Khahro, K. Tabbassum, A.M. Soomro, L. Dong, X. Liao. Evaluation of wind power production prospective and Weibull parameter estimation methods for Babaurband, Sindh Pakistan. Energy Conversion and Management. 78 (2014) 956-67.

[37] O. Alavi, A. Sedaghat, A. Mostafaeipour. Sensitivity analysis of different wind speed distribution models with actual and truncated wind data: a case study for Kerman, Iran. Energy Conversion and Management. 120 (2016) 51-61.

[38] E.K. Akpinar, S. Akpinar. A statistical analysis of wind speed data used in installation of wind energy conversion systems. Energy conversion and management. 46 (2005) 515-32.

[39] E.C. Morgan, M. Lackner, R.M. Vogel, L.G. Baise. Probability distributions for offshore wind speeds. Energy Conversion and Management. 52 (2011) 15-26. 
[40] V.L. Brano, A. Orioli, G. Ciulla, S. Culotta. Quality of wind speed fitting distributions for the urban area of Palermo, Italy. Renewable Energy. 36 (2011) 1026-39.

[41] B. Safari. Modeling wind speed and wind power distributions in Rwanda. Renewable and Sustainable Energy Reviews. 15 (2011) 925-35.

[42] N. Masseran, A.M. Razali, K. Ibrahim. An analysis of wind power density derived from several wind speed density functions: The regional assessment on wind power in Malaysia. Renewable and Sustainable Energy Reviews. 16 (2012) 6476-87.

[43] J.A. Carta, P. Ramirez, S. Velazquez. A review of wind speed probability distributions used in wind energy analysis: Case studies in the Canary Islands. Renewable and sustainable energy reviews.

$53913(2009)$ 933-55.

540 [44] N. Masseran. Evaluating wind power density models and their statistical properties. Energy. 84

541 (2015) 533-41.

542 [45] C. Forbes, M. Evans, N. Hastings, B. Peacock. Statistical distributions. John Wiley \& Sons2011.

543 [46] T. Chai, R.R. Draxler. Root mean square error (RMSE) or mean absolute error (MAE)?

544 Geoscientific Model Development Discussions. 7 (2014) 1525-34.

545

546

547

548

549

550

551

552

553

554

555

556

557

558

559

560

561

562

563

564

565

566

567

568

569

570

571

572

573

574

575

576

577

578

579

580

581

[47] T. Tjur. Coefficients of determination in logistic regression models-A new proposal: The coefficient of discrimination. The American Statistician. 63 (2009) 366-72.

[48] E. Kavak Akpinar, S. Akpinar. A statistical analysis of wind speed data used in installation of wind energy conversion systems. Energy Conversion and Management. 46 (2005) 515-32.

[49] D.J. Spiegelhalter, N.G. Best, B.P. Carlin, A. Van Der Linde. The deviance information criterion: 12 years on. Journal of the Royal Statistical Society: Series B (Statistical Methodology). 76 (2014) 485-93. [50] D.K. Pauler. The Schwarz criterion and related methods for normal linear models. Biometrika. 85 (1998) 13-27.

[51] E. Erdem, J. Shi. ARMA based approaches for forecasting the tuple of wind speed and direction. Applied Energy. 88 (2011) 1405-14.

[52] V.-T. Tran, T.-H. Chen. Wind energy resources on Phuquoc island, Vietnam. Energy Sources, Part A: Recovery, Utilization, and Environmental Effects. 38 (2016) 1612-9.

[53] N.M. Al-Abbadi. Wind energy resource assessment for five locations in Saudi Arabia. Renewable Energy. 30 (2005) 1489-99.

[54] M. Elamouri, F.B. Amar. Wind energy potential in Tunisia. Renewable energy. 33 (2008) 758-68.

[55] G. Gualtieri, S. Secci. Extrapolating wind speed time series vs. Weibull distribution to assess wind resource to the turbine hub height: A case study on coastal location in Southern Italy. Renewable Energy. 62 (2014) 164-76.

[56] A. Bagavathsingh, C. Srinivas, R. Baskaran, B. Venkatraman, M. Sardar. Wind direction dependent vertical wind shear and surface roughness parameter in two different coastal environments. Proceedings of the international conference on radiological safety in workplace, nuclear facilities and environment: book of abstracts 2016.

[57] M.E. Okorie, F. Inambao, Z. Chiguvare. Evaluation of wind shear coefficients, surface roughness and energy yields over inland locations in Namibia. Procedia Manufacturing. 7 (2017) 630-8.

[58] O.N. Laban, C.M. Maghanga, K. Joash. Determination of the Surface Roughness Parameter and Wind Shear Exponent of Kisii Region from the On-Site Measurement of Wind Profiles. Journal of Energy. 2019 (2019).

[59] M. Hussain. Dependence of power law index on surface wind speed. Energy conversion and management. 43 (2002) 467-72.

[60] F. Fazelpour, N. Soltani, M.A. Rosen. Wind resource assessment and wind power potential for the city of Ardabil, Iran. International Journal of Energy and Environmental Engineering. 6 (2015) 4318.

[61] O. Alavi, K. Mohammadi, A. Mostafaeipour. Evaluating the suitability of wind speed probability distribution models: A case of study of east and southeast parts of Iran. Energy Conversion and Management. 119 (2016) 101-8.

[62] K. Tar. Some statistical characteristics of monthly average wind speed at various heights. Renewable and Sustainable Energy Reviews. 12 (2008) 1712-24. 
[63] I.T. Togrul, C. Ertekin. A statistical investigation on the wind energy potential of Turkey's geographical regions. Energy Sources, Part A: Recovery, Utilization, and Environmental Effects. 33 (2011) 1399-421.

[64] A. Allouhi, O. Zamzoum, M. Islam, R. Saidur, T. Kousksou, A. Jamil, et al. Evaluation of wind energy potential in Morocco's coastal regions. Renewable and Sustainable Energy Reviews. 72 (2017) 311-24.

[65] Z.O. Olaofe, K.A. Folly. Wind energy analysis based on turbine and developed site power curves:

\section{0} A case-study of Darling City. Renewable Energy. 53 (2013) 306-18.

591 Figure 7 shows the distribution of average wind speed in Australia.

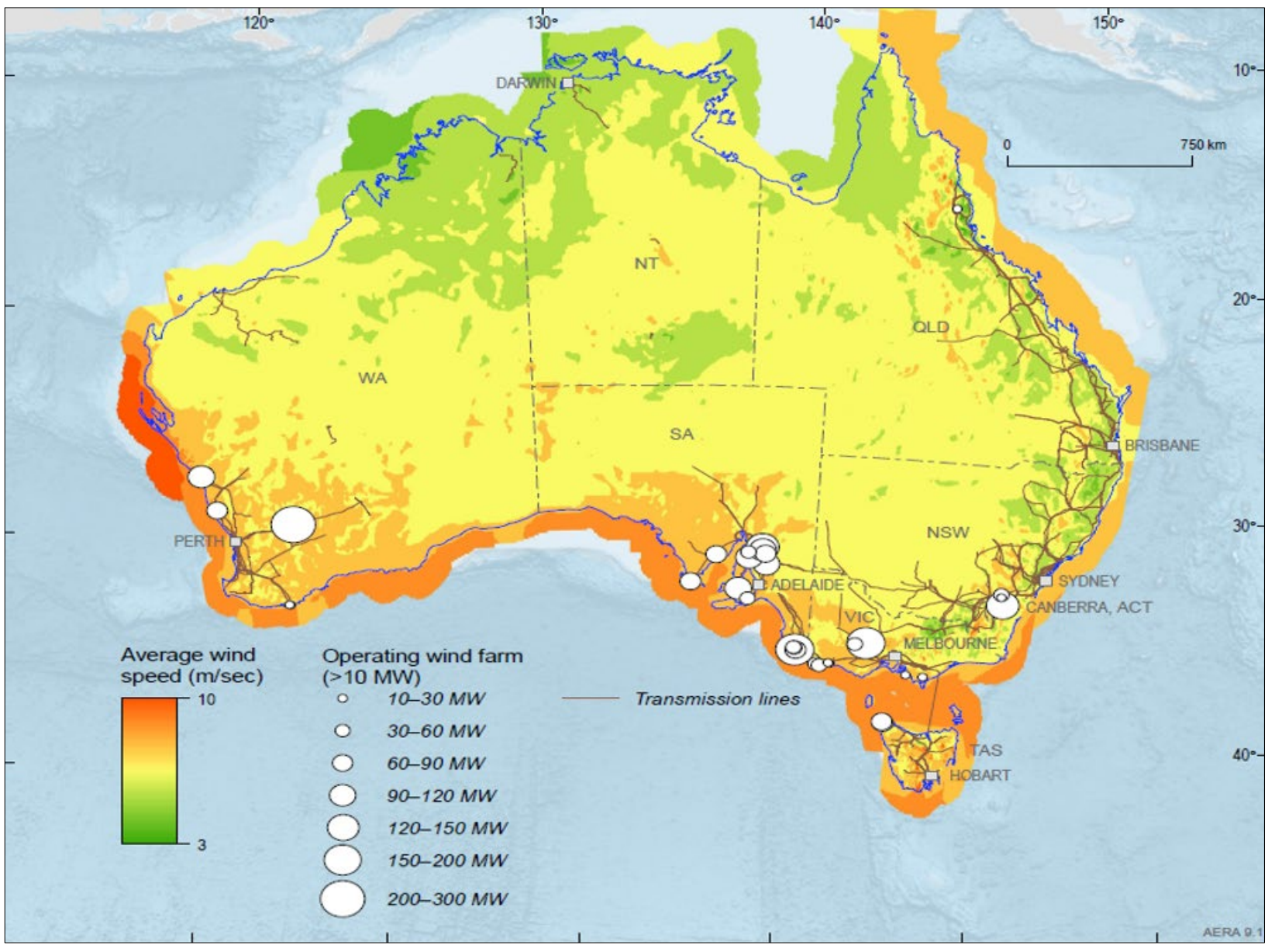

